\title{
The Influence of the Characteristics of Plastic Materials Used in the Performance of the Thoraco-Lumbar Orthoses
}

\author{
CONSTANTIN NANU ${ }^{1,2}$, ION POEATA ${ }^{2,3}$, CEZAR POPESCU ${ }^{3}$, LUCIAN EVA ${ }^{3}$, BOGDAN FLORIN TOMA ${ }^{3}$, STEFAN LUCIAN TOMA** \\ ${ }^{1}$ Clinical Emergency Hospitals, 1-3 Traian Blvd., 610003, Piatra Neamt, Romania \\ ${ }^{2}$ Grigore T Popa, University of Medicine and Pharmacy, Faculty of Medicine, 16 Universitatii Str., 700115, Iasi, Romania \\ ${ }^{3}$ Prof. Dr. Nicolae Oblu Clinical Emergency Hospital, 2 Ateneului Str., 700309, Iasi, Romania \\ ${ }^{4}$ Gheorghe Asachi Technical University of lasi, Department of Materials Engineering and Industrial Safety, 69 Mangeron, Blvd. \\ 700050, lasi, Romania
}

\begin{abstract}
The aim of the paper is to identify the of optimal plastic type used in obtaining thoraco-lumbar orthoses used in the treatments of comminutive fracture, of burst fracture type of the vertebrae in the lumbar area. For this purpose, with the help of Finite Element Analysis (FEA), a theoretical study was carried out on the influence of elastic properties of plastics, used in the achieving of lumbar orthoses, on the state of tension and on the local displacements of the bone fragments from the traumatized area under the condition of the movement from the base of extension and flexion. In the study the force of flexion, the force of extension and the elastic modulus of plastic material varied on three levels. The theoretical results obtained were completed with clinical trials carried out on a total of 26 patients who suffer thoraco-lumbar comminutive fracture, burst fractures type, at vertebra T11 and were immobilized in Boston-type plastic orthoses made of: polypropylene (PP), rigid vinyl polychloride (PVC-D) and polytetrafluoroethylene (PTFE). As a result of observations, it was found that the use of an orthesis made from rigid plastic material, although it appears higher stresses in the traumatized zone, the displacements of bone fragments are smaller, the pains is higher in the fractured zone, the angle of kyphosis (LKA) close to the normal value and a better mobility of the spine (ODI indicator)
\end{abstract}

Keywords: Spine, Boston orthosis, polypropylene, vertebra

Due to the low manufacturing cost and the special mechanical properties, thermoplastic materials are used successfully in various sectors of activity such as automotive, electronics, aeronautics, machine building, chemical industry in the construction of various prostheses, external orthotics, etc. [1,2].

The external immobilisation of the body in orthotics made by plastics materials - the Boston orthosis type, is the most common method of treatment applicable in the case of A4 fractures type - named also burst fracture, [3, 4]. These are fractures in which the vertebral body is crushed in a minimum of 5-6 pieces due to a hard impact produced from the outside, [5]. The main advantage of the proposed treatment method is the simplicity and the low price. However, the method of treatment by thoracolumbar immobilization in Boston-type plastic orthotics is painful and allows bone fragments to move during their treatment period, so the inadequate fusion, leading to geometrical deviations of the spine, [6-8].

Studies carried out by Lee et colab. [9] have demonstrated that shifting bone fragments of burst fractured vertebrae occurs during flexion and extension movements in the sagittal and lateral plane - absolutely inevitable movements during the treatment of patients. Marwan El-Rich et al. [10] have demonstrated that the appearance of a mechanical stress state in a traumatized area causes pain and is transmitted to the central nervous system through pain receptors.

In the present paper it is carried out a theoretical study on the influence of the elastic properties of the plastic materials used in the Boston lumbar orthosis type- used in the case of burst fracture treatments - at the T11 vertebrae level. The theoretical study is completed by clinical observations performed on a total of 26 patients who underwent thoraco-lumbar spinal comminutive lesions at the T11 vertebrae level and who were immobilized in a Boston-style corset.

\section{Experimental part}

Materials and Methods

Finite element analyses of study

In order to calculate the tension in the spine and local displacement of bone fragments - in the condition of the body immobilization in a Boston corset type it was used a method for finite element analysis (FEA), respectively Ansys Multiphysics software (ANSYS Inc., Canonsburg, PA) [11, 12]. For this, a two-dimensional model (fig. 1), detailed in the spine area, which contains in the thoraco-lumbar area, it was made a fracture of burst fracture type, at the T11 level vertebra.

The vertebrae were drawn in longitudinal axial section according to computed tomography of the spine, made on a 25-year-old male patient - similar to the model carried out by Frank Heuer et colab, [13]. At the vertebral column level were represented: the intervertebral disc, lower and upper end plates, the longitudinal anterior ligaments, the posterior longitudinal ligament, flavum ligament, interspinous ligament and supraspinous ligament. The vertebral disc (fig. 1) was considered as an assembly composed of: pulpous nucleus - made from field - an incompressible fluid (NS); an annular fibrosis (AS) assimilated with a hyper elastic composite material, fibers reinforced; cartilaginous endplates (EP) - assimilated with a composite material - similar to the model made by Rohlmann et colab., [14].

*email: stltoma@gmail.com 


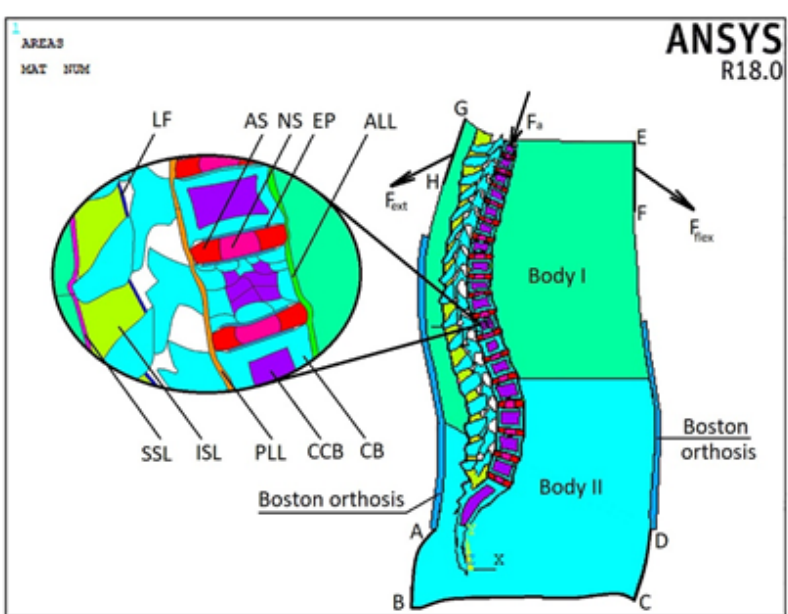

Fig. 1. Fracture model used to study tensions and local displacements stabilized by Boston orthosis: LF - ligamentum flavum; ISL - interspinous ligament; SSL - supraspinous ligament; CB - cortical bone CCB - Cancellous bone; AS - annulus; NSnucleus; EP -endplate; detail vertebra T11

The physical properties of the materials used were assumed to be isotropic and homogeneous and the data were taken from the technical literature, [15-21] (table 1). The ligaments were considered to be viscous - elastic and isotropic, for their modelling using elastic elements available in the ANSYS program (table 2).

In the section plane chosen to represent the model, the chest and abdomen were not represented. Their homogeneous and isotropic behaviour has been simplified by attributing different properties to Corp. I and Corp II afferent materials (table 1). All elements of the model (cortical bone, spongy bone, ligaments, body I, body II, orthosis) were discretized using the two-dimensional solid elements shown in table 2 . The faces of the articulations have been treated as a contact problem nonlinear, twodimensional, without friction.

In order to be conformity with the kinematics and the charge of the column in vivo, elementary positions such

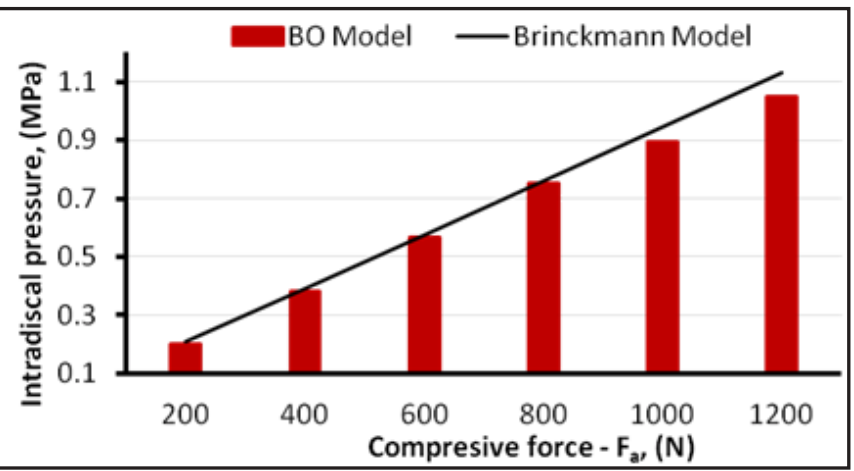

Fig.2. The pressure values inside the L4-L5 vertebral disc, in the condition of applying of an axial compression force, measured in vivo - Brinckmann model and calculated with the help of finite elements - using an external fixation through a Boston orthosis (BO Model)

as: the flexion and the body extension specific to the normal activities performed in everyday life, were simulated. Thus, the model has been stiffened along the A-B-C-D contour and subjected to subjected to flexion $\left(\mathrm{F}_{\mathrm{ftex}}\right)$ and extension forces $\left(\mathrm{F}_{\text {xy }}\right)$, applied along the $\mathrm{EF}$ and $\mathrm{GH}$ lines (fig. 1), inclined at an angle of 60p to the negative direction of the Oy axis - necessary to simulate the movement of flexion respectively the body extension.

Validation of the considered model was performed by applying a compressive axial force $\left(F_{a}\right)$ at the vertebra T1 level and calculating average pressure value inside the intervertebral disc between the vertebrae T4-T5. The obtained results were compared with the results measured by Brinckmann et al. [22] - and are presented in figure 2.

It can be seen that a good degree of compliance has been achieved since the calculated values are lower by $0.09 \mathrm{MPa}$ than the Brinckmann measured values.

In the considered study it was assumed that the orthosis has a thickness of $4 \mathrm{~mm}$, the flexion force, the extension force and the material of which the orthosis was made varied on three levels (table 3).

\begin{tabular}{|c|c|c|c|c|}
\hline Material & $\begin{array}{l}\text { Young's Modulus, } \\
\text { (MPa) }\end{array}$ & $\begin{array}{l}\text { Poisson } \\
\text { ratio }\end{array}$ & $\begin{array}{c}\text { Density } \\
{\left[\mathrm{Kg} / \mathrm{mm}^{3}\right]}\end{array}$ & $\begin{array}{c}\text { Cross section } \\
\left(\mathrm{mm}^{2}\right)\end{array}$ \\
\hline \multicolumn{5}{|l|}{ Vertebra } \\
\hline Cortical bone & 12000 & 0.3 & $1.83 \mathrm{E}-06$ & \\
\hline Cancellous bone & 200 & 0.2 & $0.17 \mathrm{E}-06$ & \\
\hline Posterior bony elements & 3500 & 0.25 & $1.06 \mathrm{E}-06$ & \\
\hline \multicolumn{5}{|l|}{ Disc } \\
\hline Annulus & 8.4 & 0.45 & $1.20 \mathrm{E}-06$ & \\
\hline Nucleus & 1.0 & 0.495 & $1.0 \mathrm{E}-06$ & \\
\hline Endplate & 24.0 & 0.4 & & \\
\hline \multicolumn{5}{|l|}{ Ligament } \\
\hline ALL & 11.4 & 0.4 & $1.0 \mathrm{E}-06$ & 63.7 \\
\hline PLL & 9.12 & 0.4 & $1.0 \mathrm{E}-06$ & 20 \\
\hline $\mathrm{LF}$ & 5.7 & 0.4 & $1.0 \mathrm{E}-06$ & 40 \\
\hline ISL & 4.6 & 0.4 & $1.0 \mathrm{E}-06$ & 40 \\
\hline $\mathrm{SSL}$ & 8.55 & 0.4 & $1.0 \mathrm{E}-06$ & 30 \\
\hline Body I & 9000 & 0.3 & - & \\
\hline Body II & 2000 & 0.38 & - & \\
\hline
\end{tabular}

Table 1

MATERIAL PROPERTIES USED IN FEM OF THE LUMBAR SPINE [15-18]

\begin{tabular}{|l|c|c|}
\hline Intervertebral body & & Element type \\
\hline Vertebrae & Cortical bone, Cancellous bone & Plane 183 \\
\hline Disc & Annulus, Nucleus, Endplate & Plane 82 \\
\hline Ligament & ALL, PLI, SSL & Plane 82 \\
\hline Body & LF, ISL & Shell 93 \\
\hline Orthosis & Body I, Body II & Plane 183 \\
\hline
\end{tabular}

Table 2

ELEMENT TYPE USED IN THE FEM OF THE SPINE 


\begin{tabular}{|c|c|c|c|c|c|c|}
\hline Model & $\begin{array}{l}\text { Experiment } \\
\text { code }\end{array}$ & Material & Movement & $\begin{array}{l}\text { Force, } \\
\text { (N) }\end{array}$ & $\begin{array}{c}\text { Elasticity } \\
\text { modulus, }[\mathrm{MPa}]\end{array}$ & $\begin{array}{l}\text { Density, } \\
{\left[\mathrm{kg} / \mathrm{cm}^{3}\right]}\end{array}$ \\
\hline \multirow{18}{*}{$\begin{array}{l}\text { Fixare } \\
\text { exterioara } \\
\text { in corset } \\
\text { tip Boston }\end{array}$} & S-101 & PP & \multirow{9}{*}{ Flexie } & \multirow{3}{*}{300} & 1700 & 0.9 \\
\hline & S-102 & PVC-D & & & 2800 & 1.4 \\
\hline & S-103 & PTFE & & & 3200 & 2.2 \\
\hline & S-104 & PP & & \multirow{3}{*}{500} & 1700 & 0.9 \\
\hline & S-104 & PVC-D & & & 2800 & 1.4 \\
\hline & S-106 & PTFE & & & 3200 & 2.2 \\
\hline & S-107 & $\mathrm{PP}$ & & \multirow{3}{*}{700} & 1700 & 0.9 \\
\hline & $\mathrm{S} 108$ & PVC-D & & & 2800 & 1.4 \\
\hline & S-109 & PTFE & & & 3200 & 2.2 \\
\hline & S-110 & $\mathrm{PP}$ & \multirow{9}{*}{ Extensie } & \multirow{3}{*}{300} & 1700 & 0.9 \\
\hline & S-11 & PVC-D & & & 2800 & 1.4 \\
\hline & S-112 & PTFE & & & 3200 & 2.2 \\
\hline & S-113 & $\mathrm{PP}$ & & \multirow{3}{*}{500} & 1700 & 0.9 \\
\hline & S-114 & PVC-D & & & 2800 & 1.4 \\
\hline & S-115 & PTFE & & & 3200 & 2.2 \\
\hline & $\mathrm{S} 116$ & PP & & \multirow{3}{*}{700} & 1700 & 0.9 \\
\hline & S-117 & PVC-D & & & 2800 & 1.4 \\
\hline & S-118 & PTFE & & & 3200 & 2.2 \\
\hline
\end{tabular}

In each experıment, were calculated, using the AIVSYS program, the total von Mises tensions and the displacement of the bone fragments 1, 3, 4 and 6 at the level of fractured vertebra T11 (fig. 3).

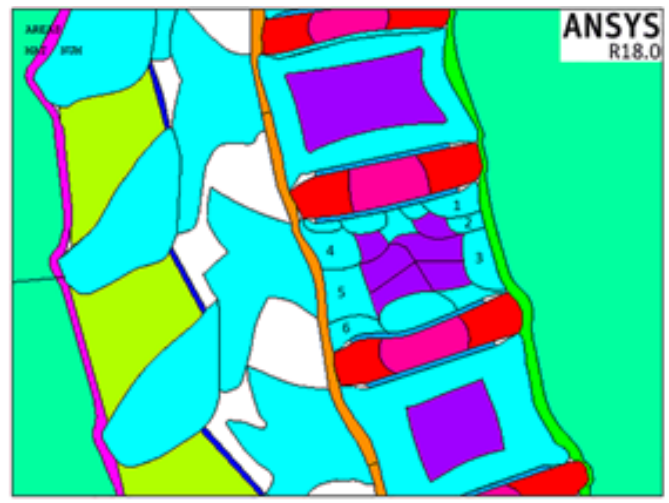

Fig. 3. Vertebral fragments - components of the fractured vertebra T11

\section{Clinical study}

At the Neurosurgery Clinic of Prof. N. Oblu lasi clinical observations were performed on 26 patients who have suffered toraco-lumbar fracture type A4 (burst fractures) on the T11 vertebra and who were immobilized in Bostontype plastic orthoses. The trauma was caused by road accidents $(53.84 \%)$, falls from height $(30.7 \%)$, sports accidents (1.5\%) or other domestic causes (rest). The patients included in the study didn't have neurological deficiencies, posterior ligament lesions, pathological fractures on the diseased bone, polytrauma and were having the angle of local kyphosis of less than 30p.

All patients were treated by external immobilization through a Boston-type ortheses made of different thermoplastic materials as follows: 12 patients were immobilized in the polypropylene orthosis(PP), 8 patients wore the ortheses made by rigid polymerized vinyl chloride
(PVC-D) and 6 patients were immobilized in polytetrafluoroethylene orthotics (PTFE). The materials used in the experiments did not produce dermal reactions because the patients were protected by wearing a textile T shirt. Boston orthoses were made in the laboratory of ICEFS COM SRL Savinesti, Neamt.

The patient group was periodically evaluated at 3, 6 and 12 months by standard radiography analysis in orthostatism. The profile images calculated the segmentation angle (LKA) - using the Cobb method and the anterozide height (AVH). The pain was evaluated by the Visual Analogue Scale (VAS) scale and the functional status indicator of spinal column mobility was evaluated using the Oswestry Dysability Index (ODI) scale.

\section{Results and discussions}

The results obtained in this study are presented in two parts: in the first part are presented the results obtained after the finite element analysis of the stress state at the vertebrae level and the bone fragments displacementfrom the T11 fractured vertebra level, in the conditions presented in table 3; in the second part are presented the results of the observations and clinical investigations performed on groups of patients who suffered fractures of type A4 and were treated by external immobilization in a Boston corset made of the materials presented in clinical study.

\section{Results of the MEF analysis}

The model carried out in figure 1 allows the determination of tension state, elastic deformations and local displacements performed at vertebra T11 level.

From figure $4 a-c$ it can be seen that in the case of using an orthosis made of PTFE and of performing a flexing motion in a sagittal plane, the value of the total tension of von Mises is higher than in the case of the use of a PP or PVC-D. orthesis. By the analysis of figure $5 a-c$ it is observed that in the case of execution of an extension movement, 

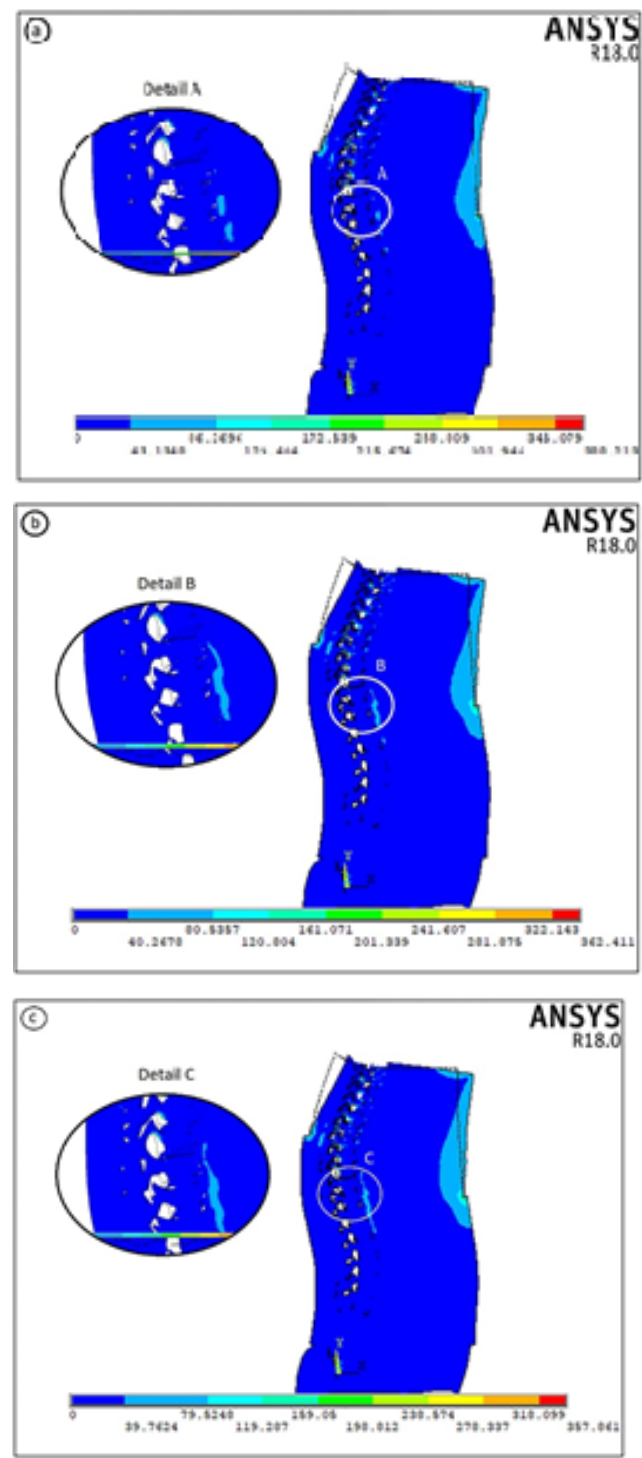

Fig. 4. Variation of von Mises stress in the case of stabilizing a fracture with a Boston orthosis Boston fabricated from: a) PP; b) PVC-D; C) PTFE and performing a flexion movement ( $F=700 \mathrm{~N})$

the values of von Mises tensions are close in the three cases; higher stresses being recorded in case of immobilization in the of orthesis made of PTFE. In all the cases presented, it is noticed that the value of von Mises total stresses in the bone fragments of the T11 vertebra, increases with the increase of the elastic modulus of the material from which the orthosis is constituted. It can be affirmed that the high rigidity of the orthotic material imprints in the body, respectively at the level of the fractured vertebra T11, higher total tensions von Mises.
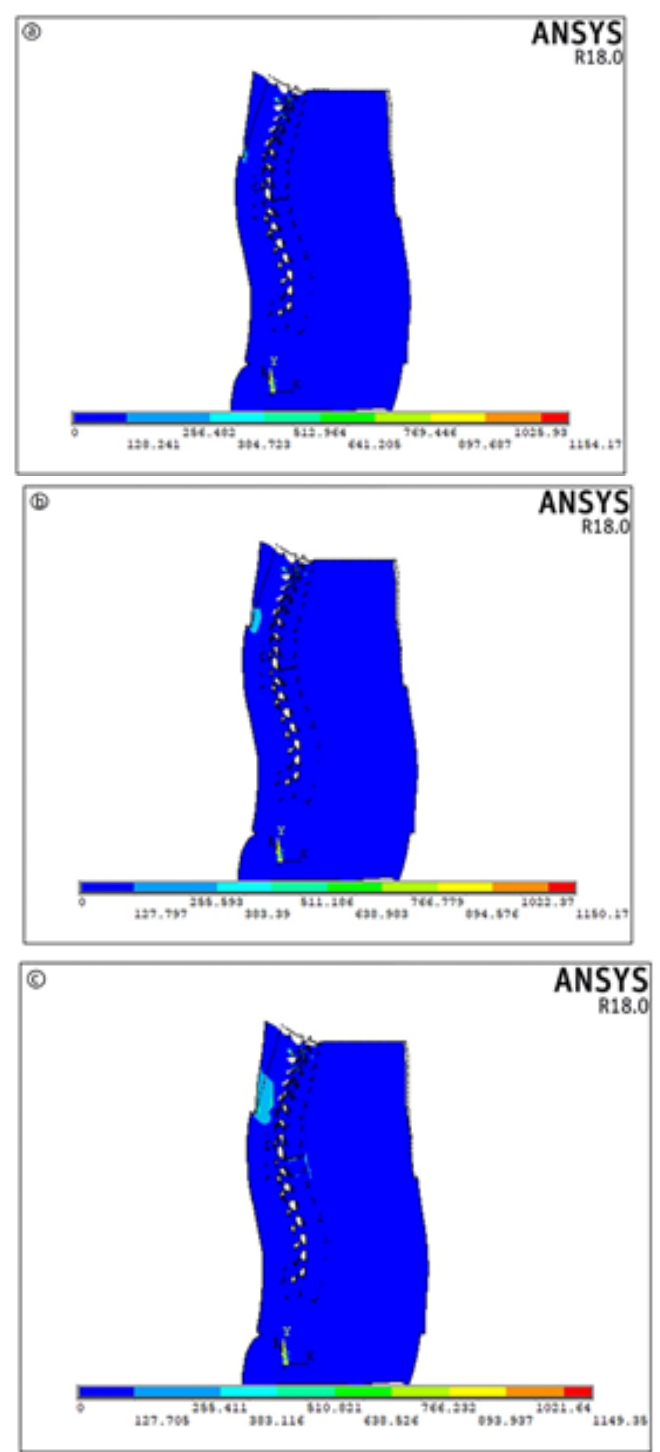

Fig. 5. Variation of von Mises stress in the case of stabilizing a fracture with a Boston orthosis Boston fabricated from: a) PP; b) PVC-D; C) PTFE and performing a extension movement ( $F=700 \mathrm{~N})$

The local displacement of the bone fragments $1,3,4$ and 6 (fig.2) of the T11 component vertebra, in the case of the flexion movement, respectively extension movement is presented in figure 6 . It can be observed that, both in the case of the extension movement and in the case of performing the flexion movement of the local displacements of the bone fragments are smaller when using a PTFE orthesis.

It can be suggested that the high rigidity of the orthesis transmits higher tensions in the fractured vertebra T11 and smaller local displacements of the bone fragments from the component of the traumatized vertebra T11.

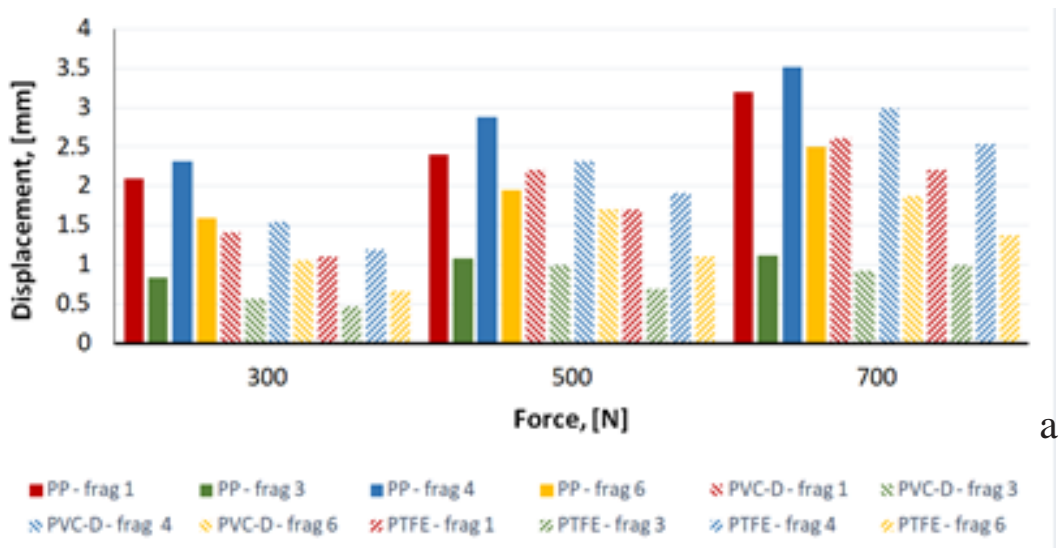

Fig. 6. Local displacement of bone fragments 1 , 3,4 and 6 in the condition of execution: a) flexion motion 


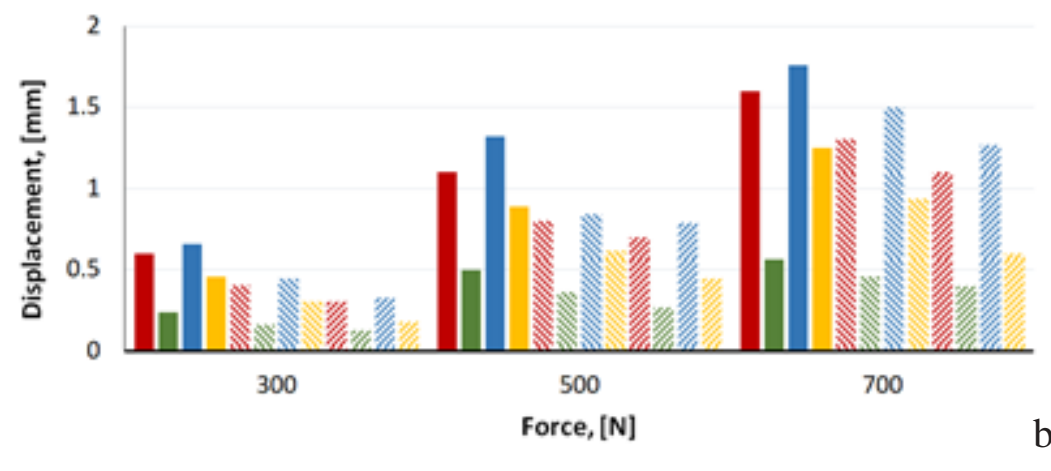

Fig. 6. Local displacement of bone fragments 1, 3, 4 and 6 in the condition of execution: b) extension motion - with force $\mathrm{F}=700 \mathrm{~N}$

=PP-frag 1 =PP-frag $3 \quad$ =PP-frag $4 \quad$ =PP-frag 6 \&PVC-D-frag 1 × PVC-D-frag 3 XPVC-D-frag 4 × PVC-D-frag 6 क्PTFE-frag $1 \quad$ कPTFE-frag 3 कPTFE-frag 4 क PTFE-frag 6

Table 4

RESULTS OF CLINICAL EVALUATION OF THE PATIENT

\begin{tabular}{|c|c|c|c|c|c|c|c|c|c|c|}
\hline \multirow{2}{*}{ Grup } & \multicolumn{3}{|c|}{ Evaluare LKA dupa } & \multicolumn{3}{c|}{ Evaluare AVH dupa } & \multicolumn{4}{c|}{ Media VAS } \\
\cline { 2 - 11 } & 3 luni & 6 luni & 12luni & 3 luni & 6 luni & 12luni & Initial & 3luni & 6luni & 12luni \\
\hline I-PP & $10.8^{0}$ & $13.53^{0}$ & $16.42^{0}$ & $67.3 \%$ & $63.2 \%$ & $60.4 \%$ & 9.1 & 6.3 & 3.4 & 1.8 \\
\hline II-PVC-D & $14.22^{0}$ & $18.2^{0}$ & $21.16^{0}$ & $57.4 \%$ & $52.5 \%$ & $50.7 \%$ & 9.2 & 6.6 & 3.7 & 2.0 \\
\hline II - PTFE & $19.35^{\circ}$ & 22.42 & $25.63^{\circ}$ & $48.7 \%$ & $44.3 \%$ & $41.5 \%$ & 9.1 & 7.2 & 4.8 & 2.1 \\
\hline
\end{tabular}

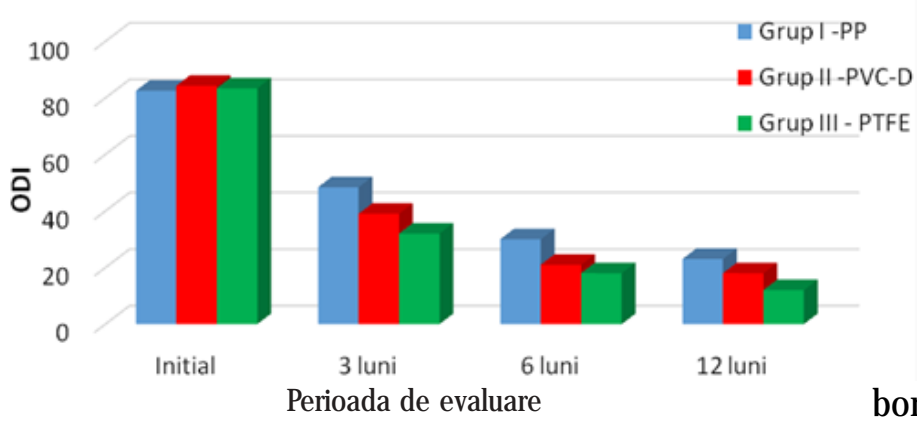

Fig 7. Evolution of functional status (ODI) of patients by evaluation at 3, 6 and 12 months

bone fragments of the vertebra T11 are moving on relative longer distances changing their position. Reconstruction the vertebra by the fusion of the bone fragments, leads to

Results of clinical analyses

The angle of local kyphosis (LKA) and the anterozide height (AVH) were analyzed and compared on the three groups of patients. The results obtained from the investigations developed on the patients who suffered from burst fracture A4, at the T11 vertebra level and who were immobilized in Boston-type plastic orthosis are presented in table 4.

Itcan be noticed that in the condition of using of a corset made of material with a high elasticity modulus, the height of the anterozide (AVH) decreases and the angle of local kyphosis (LKA) increases. The pain indicator - VAS has a decreasing trend, tending to the value of 2 after a 12-month period - acceptable for patients who have suffered spinal injuries.

From figure 7 it can be seen that higher mobility of the spine presents patients who have been immobilized in orthotics made of plastics with high elasticity modulus. For all three groups, the functional status of patients carried out through ODI assessment, has a decreasing trend, stabilized below the value of 20 - considered admissible value for patients who have suffered from spinal injuries.

At the periodic evaluation, by macroscopic analysis of orthotics - it was observed that a number of 5 Boston orthoses made of PTFE showed cracks in the upper abdominal area due to bending efforts induced in the material by flexion movements in sagittal plane.

By concatenating the results, it can be suggested that in the case of fracture, burst fractures type, by immobilizing with a Boston type corset, characterized by a low modulus of elasticity, after the flexion or extension movements, the the modification of geometric shape of this, angle of local kyphosis (LKA), and implicitly the geometry of the spine.

\section{Conclusions}

As a result of the research we can affirm that:

- by using a plastic orthesis with low elasticity, in the treatment of A4 burst fractures type, after developing flexion movements, respectively the extension in the sagittal plane, appear large displacements of the bone fragments of the fractured vertebra (fig. 5), aspects that lead to the decrease of the angle of local kyphosis (LKA) (table 4) and implicit of the geometry of the spine. As a consequence of application of this type of treatment, the mobility of the spine - carried out through ODI evaluation is within admissible limits (fig. 6);

- The use of a orthesis made by a material with high elasticity modulus- PFTE respectively, imprints higher stresses in the traumatized lumbar area (fig. 4), small shifts of bone fragments from fractured vertebrae - T11 (fig. 5), higher pain in fractured area - table VAS indicator 4 and greater LKA angle kyphosis, close to the normal value $30^{\circ}$ and better spinal mobility (ODI <20). However, although the treatment of vertebral spine A4 fractures by a more rigid orthosis is more painful, it allows restoration of the column geometry and easier postraumatic recovery.

\section{References}

1. E. GHITA, G.R., GILLICH, I., BORDEASU, M., VODA, TROI,C., Mat. Plast., 44, no. 2, 2007, p. 158.

2. GILLICH, G.R., SAMOILESCU, G., BERINDE, F.C., CHIONCEL, C.P., Mat. Plast.., 44, no. 1, 2007, p. 18. 
3. SCHULTZ, A.B., ANDERSSON, G.B., Spine, 6, 1981, p. 76.

4. HEUER, F., SCHMIDT, H., KLEZL, Z., CLAES, L., WILKE, H.J., J ournal of Biomechanics, 40 (2), 2007, p. 271.

5. KING, A.I., Injury to the Thoracolumbar Spine and Pelvis Accidental Injury: Biomechanics and prevention, 2nd edn, Springer, New York, 2002.

6. MAGERL, F., AEBI, M., GERTZBEIN, S.D., HARMS, J., NAZARIAN, S., Eur Spine J, 3, 1994, p. 184.

7. BAKER, R.J., PATEL, D., Prim Care, 32, 2005, p. 201.

8. SHIRAZI-ADL, A., AHMED, A.M., SHRIVASTAVA, S.C., Spine, 11, 1986,

p. 914.

9. LEE, C.K., KIM, Y.E., LEE, C.S., HONG, Y.M., JUNG, J.M., GOEL, V.K., Spine, 25, 2000, p. 2431.

10. EL-RICH, M., ARNOUX, P.J., WAGNAC, E., BRUNET, C., Journal of Biomechanics, 42, 2009, p. 1252

11. NAKASONE, Y., YOSHIMOTO, S., STOLARSKI, T.A., Eng. Anal. ANSYS Softw. 2006, 215.

12. TOMA, S.L., BEJ INARIU, C., BACIU, R., RADU, S., Surface $\&$ Coatings Technology, 220, 2013, p. 266.

13 HEUER, F., SCHMIDT, H., WILKE, H.J ., J ournal of Biomechanics, 41, 2008, p. 1953.
14. ROHLMANN, A., ZANDER, T., BERGMANN, G., Spine, 30, 2005, p. 738.

15. WAGNAC, E, AUBIN, C.E., EL-RICH, M., Med Eng Phys., 133, no. 10, 2011, 101007 .

16. QIU, T.X., TAN, K.W., LEE, V.S., TEO, E.C., Medical Engineering \& Physics, 28, 2006, p. 656.

17. OCHIA, R.S., TENCER, A.F., CHING, R.P., J ournal of Biomechanics, 36, 2003, p. 1875.

18. ROHLMANN, A., BAUER, L., ZANDER, T., BERGMANN, G., WILKE, H.J ., J Biomech, 39, 2006, p. 981.

19. ASAFTEI, I.V., EARAR, K., BIRSA, L.M., SANDU, I.G., LUNGU, N.C., SANDU, I., Rev. Chim. (Bucharest), 66, no. 7, 2015, p. 963.

20. TRANDAFIR, L.M., CHIRIAC, M.L., DIACONESCU, S., IONIUC, I., MIRON, I., RUSU, D., Medicine, 95, no. 44, 2016, article e5065.

21. TRANDAFIR, L.M., FRASINARIU, O.E., CHIRIAC, M.I., MIRON, I., Medical-Surgical J ournal-Revista Medico-Chirurgicala, 121, no. 2, 2017, p. 313.

22. BRINCKMANN, P., Spine, 11, no. 2, 1986, p. 149.

$\overline{\text { Manuscript received: } 21.10 .2017}$ 